\title{
PERANCANGAN DATABASE RELATIONAL PADA TOKO BUKU ONLINE
}

\author{
Al-Husain ${ }^{1}$ \\ Felita Ariyanti ${ }^{2}$ \\ Sinudarwati ${ }^{3}$ \\ Dosen STMIK Raharja Tangerang ${ }^{1,}$ Mahasiswa STMIK Raharja Tangerang ${ }^{2,3}$ \\ Jl.Jendral Sudirman No.40, Modernland, Tangerang 1,2,3 \\ e-mail: alhusain@ raharja.info ${ }^{1}$, felita@ raharja.info ${ }^{2}$, sinudarwati@ raharja.info ${ }^{3}$.
}

\begin{abstract}
ABSTRAK
Jurnal ini bertujuan untuk merancang basis data untuk mempermudah proses pembelian, dan penjualan online untuk para konsumen. Disamping itu perancangan sistem baru juga dilakukan dengan melakukan pembuatan sistem dengan menggunakan tool diantaranya Normalisasi, ERD, file database. Metodologi penelitian yang dilakukan adalah meliputi observasi langsung dan literature yang berhubungan dengan tema penelitian yang dibahas. Studi lapangan meliputi pengamatan, wawancara. Sedang studi kepustakaan dilakukan dengan penelitian kepustakaan yang relevan dengan masalah tersebut. Setelah rancangan global selesai dibuat maka dapat diketahui bahwa Pembuatan laporan yang sebelumnya dengan proses manual dengan cara menghimpun data satu per satu sehingga waktu yang disediakan tidak cukup, maka dengan rancangan basis data pengadaan laporan akan semakin mudah.
\end{abstract}

Kata Kunci : Toko buku online, Database relational, Website

\section{ABSTRACT}

Journal report titled "Designing Database at Online Bookstore" Task Journal report aims to design a database to facilitate the process of buying and selling online for consumers. Besides the new system design is also done with the preparation of the overall system that consists of data normalization, ERD, database file. The methodology of the research is includes field studies and literature. Field studies include observations, interviews. Literature study is being conducted by the research literature relevant to the problem. Once the global design is finished it can be seen that report generation earlier with manual processes by collecting data one by one so that the time allowed is not enough, then the procurement data base design report will be easier.

Keywords : Online book store, Relational database, Website 


\section{PENDAHULUAN}

Perkembangan dalam bidang teknologi informasi sudah sedemikian pesat. Sistem Infomasi berbasis web adalah salah satu sarana alternatif dalam mempermudah melayani sistem dalam toko buku yang selalu meng up to date data. Sebagai sarana layanan sistem informasi website memberikan beberapa nilai tambah bagi toko buku karena mudah diakses oleh setiap orang yang memerlukannya dan juga dengan biaya pembuatan software yang relatif mudah dibandingakan dengan software lainnya dengan adanya sistem informasi ini dapat diakses oleh manajemen toko buku dan konsumen untuk memperoleh informasi tentang buku-buku yang tersedia dalam toko buku dan tentang adanya buku-buku terbaru. Kali ini toko buku mencoba untuk membuat sistem informasi berbasis web dengan website, toko buku memberikan informasi secara cepat, akurat, dan efisien untuk mendapatkan informasi yang dibutuhkan.

\section{LANDASAN TEORI}

\section{a. Sistem Informasi}

Menurut Robert A. Leitch dan K. Roscoe Davis yang di sadur oleh Lilis Puspitawati dan Sri Dewi Anggadini(2011f:14) menyimpulkan bahwa : Sistem Informasi adalah sistem di dalam suatu organisasi yang mempertemukan kebutuhan pengelolahan transaksi harian, mendukung operasi, bersifat menajerial dan kegiatan strategi dari suatu organisasi yang menyediakan pihak luar tertentu dengan laporan-laporan yang di perlukan.

Menurut Anastasia Diana dan Lilis Setiawati(2011b:4) mengemukakan bahwa "Sistem Informasi merupakan sistem buatan manusia yang biasanya terdiri dari sekumpulan komponen baik manual maupun berbasis komputer yang beritegrasi untuk mengumpulkan, menyimpan dan mengelola data serta menyedaikan informasi kepada pihak-pihak yang berkempentingan sebagai pemakaian tersebut"

Komponen-komponen utama dalam suatu sistem informasi berbasiskan komputer terdiri dari: 1) Database, 2) Database software, 3) Aplikasi software, 4) Hardware komputer termasuk media penyimpanan, dan 5) Personal yang menggunakan dan mengembangkan system.

\section{b. Perancangan Basis data (Database)}

Proses perancangan database merupakan bagian dari micro lifecycle. Sedangkan kegiatan-kegiatan yang terdapat di dalam proses tersebut diantaranya : pengumpulan data dan analisis, perancangan database secara konsepsual, pemilihan DBMS, perancangan database secara logika (data model mapping), perancangan database secara fisik, dan implementasi sistem database. Sekarwati (2001) dalam Abdillah. Perancangan merupakan suatu hal yang sangat penting dalam pembuatan basis data.

Permasalahan dalam perancangan basis data adalah bagaimana merancang struktur logikal dan fisikal dari satu atau lebih basis data untuk memenuhi kebutuhan informasi yang diperlukan oleh pengguna sesuai dengan aplikasi-aplikasi yang ditentukan dan dapat memenuhi kebutuhan saat ini dan masa yang akan datang.

\section{c. Website}

web atau situs dapat diartikan sebagai kumpulan halaman-halaman yang digunakan untuk menampilkan informasi teks, gambar diam atau gerak, animasi, suara, dan atau gabungan dari semuanya, baik yang bersifat statis maupun dinamis yang membentuk satu rangkaian bangunan yang saling terkait, yang masing-masing dihubungkan dengan jaringanjaringan halaman. 


\section{d. Web Browser}

Menurut Kadir (2009:2) Web Browser adalah suatu perangkat lunak yang digunakan untuk dapat menjelajah internet. Perangkat lunak ini diperlukan untuk menampilkan halaman suatu website. Web Browser adalah paket software yang menyediakan interface pemakai untuk mengakses situs web internet, intranet dan ekstranet.

\section{e. Web Server}

Menurut Nugroho (2004:6) "Web Server adalah sebuah bentuk server yang khusus digunakan untuk menyimpan halaman website atau home page". Komputer dapat dikatakan sebagai web server jika komputer tersebut memiliki suatu program server yang disebut Personal Web Server (PWS). PWS ini difungsikan agar halaman web yang ada di dalam sebuah komputer server dapat dipanggil oleh komputer klien. Web server banyak macamnya diantaranya Apache, Xitami, IIS dan PWS.

\section{f. Toko Buku}

Adalah sebuah tempat dapat berupa bangunan atau ruangan yang di dalamnya menjual berbagai jenis buku yang tersusun rapi di rak-rak buku dan alat-alat yang terkait dengan buku itu sendiri. (Wikipedia)

\section{g. PHP (Personal Home Page)}

Menurut Sibero (2011:49) "PHP adalah pemrograman interpreter yaitu proses penerjemahan baris kode sumber menjadi kode mesin yang dimengerti komputer secara langsung pada saat baris kode dijalankan".

Terdapat kelebihan dari PHP itu sendiri, yaitu:

1. PHP merupakan sebuah bahasa script yang tidak melakukan kopilasi dalam penggunaanya. Tidak seperti halnya bahasa pemograman aplikasi Visual Basic dan sebagiannya.

2. PHP dapat bejalan pada web server yang dirilis oleh Microsoft, seperti IIS atau PWS juga pada Apache yang bersifat open source.

3. Karena sifatnya open source, maka perubahan dan perkembangan interpreter pada PHP lebih cepat dan mudah, karena banyak milis-milis dan developer yang siap membantu pengembangannya.

4. Jika dilihat dari segi pemahaman, PHP memiliki referensi yang begitu banyak sehingga sangat mudah untuk dipahami.

5. PHP dapat berjalan di 3 sistem operasi, yaitu Linux, Unix dan Windows dan juga dapat dijalankan secara runtime pada suatu console.

\section{METODE PENELITIAN}

Guna memperoleh data-data sebagai bahan penelitian ini, penulis telah mengumpulkan data-data dari hasil pengamatan dengan melakukan metode pengumpulan data yaitu:

\section{A. Metode Pengembangan Perangkat Lunak}

Metode yang digunakan pada pengembangan perangkat lunak ini menggunakan model waterfall yang terbagi menjadi lima tahapan, yaitu :

1. Analisis Kebutuhan Perangkat Lunak

Proses pengumpulan kebutuhan dilakukan secara intensif untuk menspesifikasikan kebutuhan perangkat lunak agar dapat dipahami perangkat lunak seperti apa yang dibutuhkan oleh user. Spesifikasi kebutuhan perangkat lunak pada tahap ini perlu untuk didokumentasikan.

2. Desain 
Desain perangkat lunak adalah proses multi langkah yang fokus pada desain pembuatan program perangkat lunak termasuk struktur data, arsiterktur perangkat lunak, representasi antarmuka, dan prosedur pengodean. Tahap ini menstralasi kebutuhan perangkat lunak dari tahap analisis kebutuhan ke representasi desain agar diimplementasikan enjadi program pada tahap selanjutnya. Desain perangkat lunak yang dihasilkan pada tahap ini juga perlu didokumentasikan.

3. Pembuatan Kode Program

Desain harus ditranslasikan ke dalam program perangkat lunak. Hasil dari tahap ini adalah program komputer sesuai dengan desain yang telah dibuat pada tahap desain.

4. Pengujian

Pengujian fokus pada perangkat lunak secara dari segi lojik dan fungsional dan memastikan bahwa semua bagian sudah diuji. Hal ini dilakukan untuk meminimalisir kesalahan (error) dan memastikan keluaran yang dihasilkan sesuai dengan yang diinginkan.

5. Pendukung (Support) atau Pemeliharaan (Maintenance)

Tidak menutup kemungkinan sebuah perangkat lunak mengalami perubahan ketika sudah dikirimkan ke user. Perubahan bias terjadi karena adanya kesalahan yang muncul dan tidak terdeteksi saat pengujian atau perangkat lunak harus beradaptasi dengan lingkungan baru. Tahap pendukung atau pemeliharaan dapat mengulangi proses pengembangan mulai dari analisis spesifikasi untuk perubahan perangkat lunak yang sudah ada, tapi tidak untuk membuat perangkat lunak baru.

\section{HASIL DAN PEMBAHASAN}

Rancangan system aplikasi penjualan online ini bertujuan untuk memasarkan produk dan dapat melakukan transaksi secara online.selain itu juga bisa dijadikan sebagai sebagai media untuk menyediakan berbagai macam informasi yang berkaitan dengan produk penjualan serta sebagai media untuk memperluas penjualan dalam mencari pelanggan.

\section{A. Analisa Kebutuhan}

Pada website pemesanan yang dilakukan secara online. Pelanggan memilih produk apa saja yang akan dibeli pada halaman produk. Sebelum membeli, pengunjung diminta mendafatar pada halaman daftar untuk mengisi data pribadi yang lengkap agar administrator dapat mengetahui alamat dan nomor telepon agar dapat melakukan pengiriman barang yang dipesan.

Dalam pembuatan toko online ini analisa kebutuhan sangatlah penting agar web yang dibuat menjadi lebih baaik sistemnya dan dapat dengan mudah digunakan oleh pengguna.

A. Kebutuhan pengguna dari web ini ada 2 bagian yaitu :

1. Pengguna sebagai Pengunjung

Dimana Pengunjung dapat melakukan kegiatan sebagai berikut:

a. Pengunjung dapat melihat semua produk yang dijual.

b. Pengunjung dapat melihat produk terbaru.

c. Pengunjung dapat melakukan login member atau daftar member.

d. Pengunjung dapat melakukan transaksi pembelian produk dengan melihat keranjang belanja.

e. Pengunjung bisa menentukan jumlah barang yang dipesan.

f. Pengunjung dapat membeli produk lebih dari satu dan membatalkan pembelian.

g. Pengunjung dapat melihat cara pembelian.

h. Pengunjung dapat melakukan ubah password

i. Pengunjung dapat melakukan pengolahan akun pribadi. 
j. Pengunjung dapat melakukan konfirmasi pembayaran

2. Pengguna sebagai Admin

Dimana Admin dapat melakukan kegiatan sebagai berikut:

a. Admin dapat mengupdate profil Toko Buku online

b. Admin dapat menambah, mengedit, serta menghapus kategori produk

c. Admin dapat menambah, mengedit, serta menghapus produk

d. Admin dapat melihat pemesanan, serta mengubah status pemesanan

e. Admin dapat melihat data hubungi kami di halaman administrator

f. Admin dapat melihat data penjualan

g. Admin dapat mengubah password admin

h. Admin dapat melakukan pengolahan ongkos kirim

i. Admin dapat melihat data penjualan

j. Admin dapat mengubah cara pemesanan/pembelian

\section{B. Perancangan Perangkat Lunak}

Berikut ini perancangan perangkat lunak untuk pengembangan sistem informasi penjualan pada Toko buku Online berbasis web :

\section{Rancangan Antar Muka}

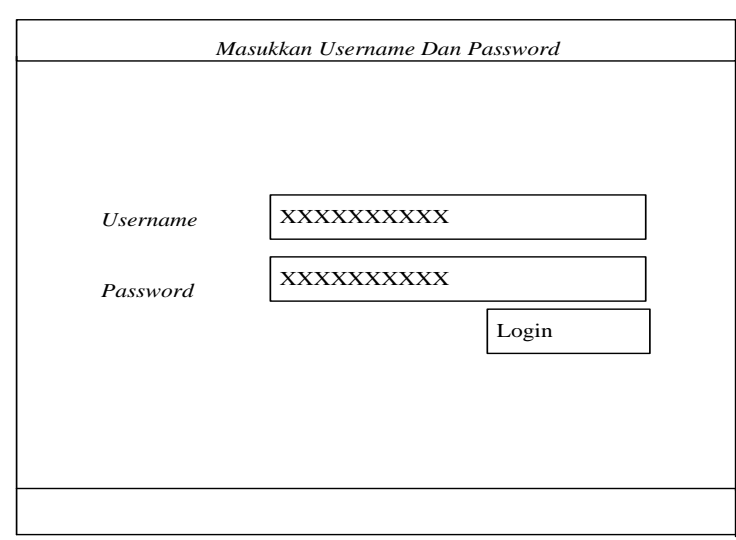

Gambar 1

Rancangan Antar Muka Login Admin

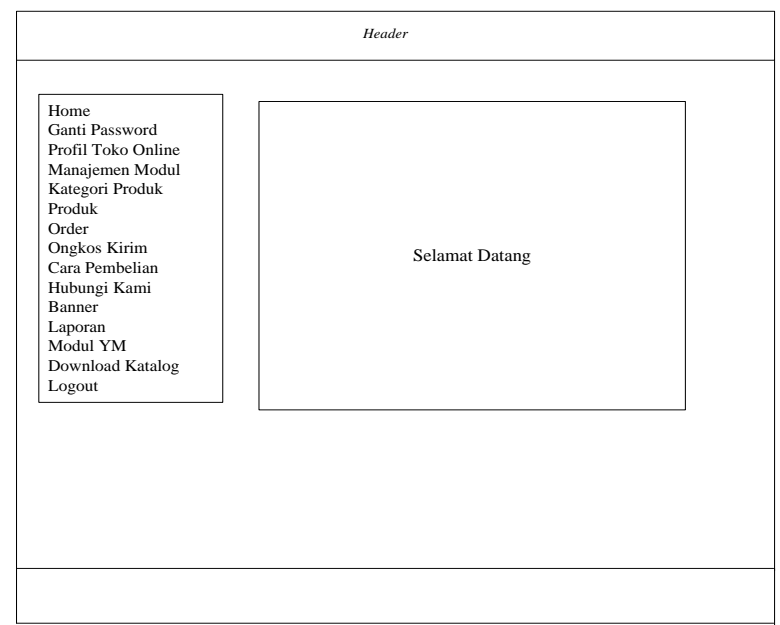

Gambar 2

Rancangan Antar Muka Home Admin 


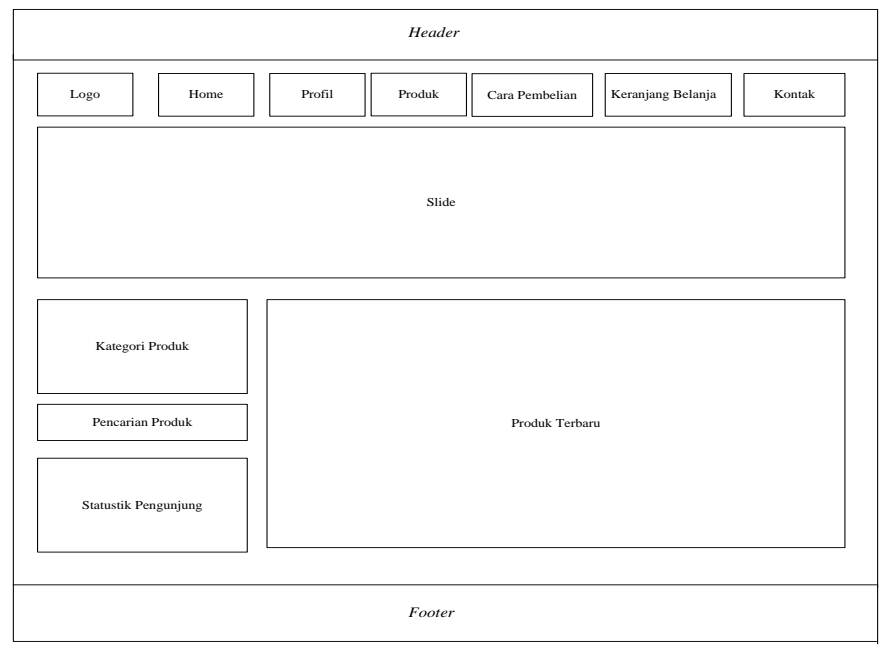

Gambar 3

Rancangan Antar Muka Home User

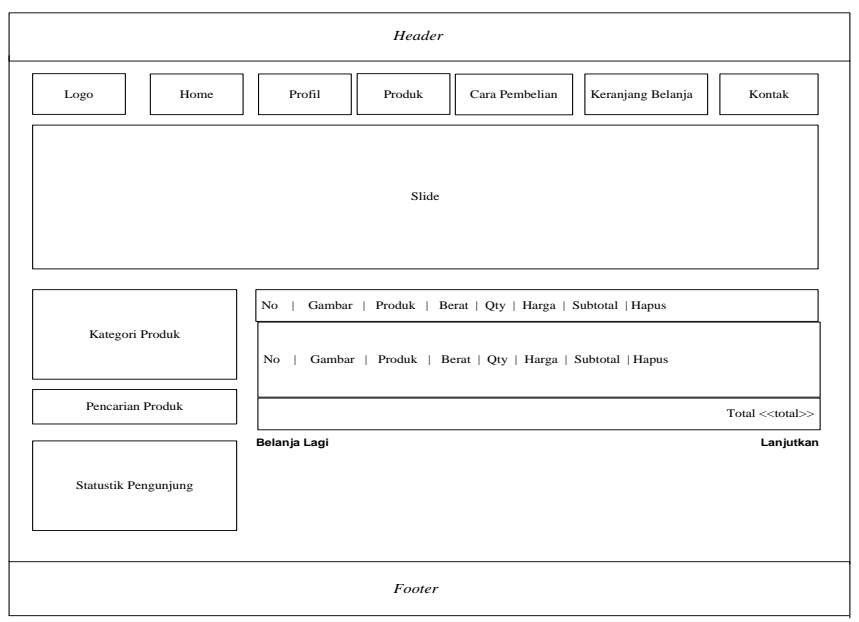

Gambar 4

Rancangan Antar Muka Konfirmasi

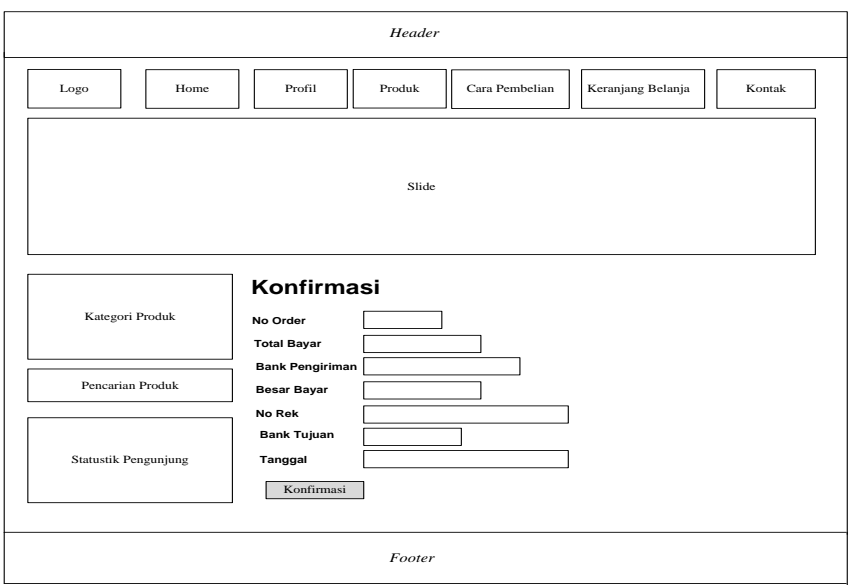

Gambar 5

Rancangan Antar Muka Konfirmasi 


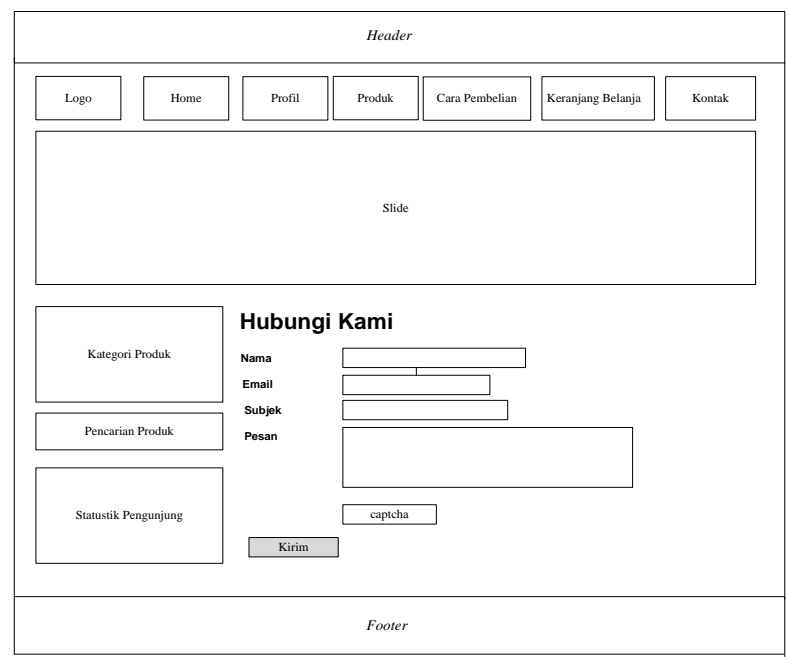

Gambar 6

Rancangan Antar Muka Kontak

D. Rancangan Basis Data

Entity Relationship Diagram

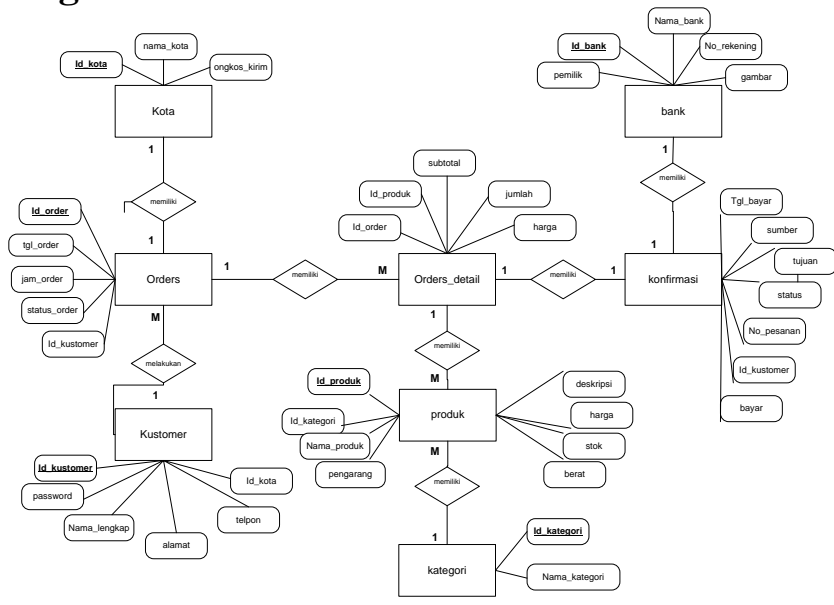

Gambar 7 Entity Relationship Diagram

\section{Logical Relational Structure}

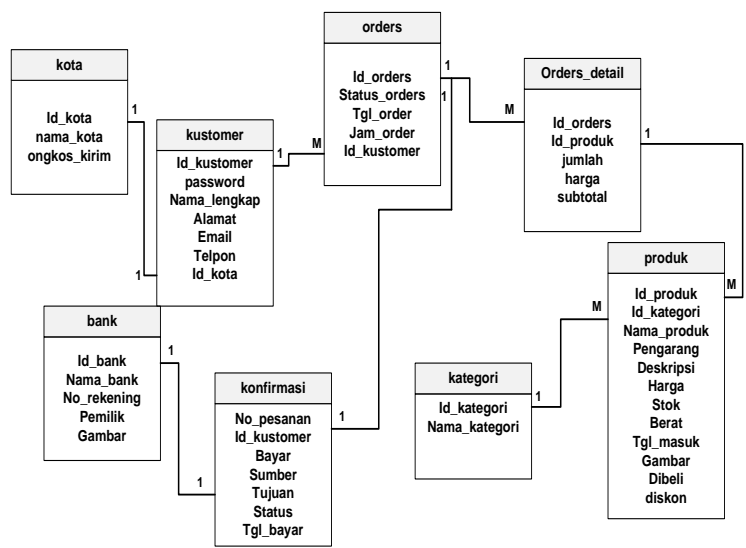

Gambar 8 Logical Relational Structure 


\section{A. Struktur Navigasi Tampilan User}

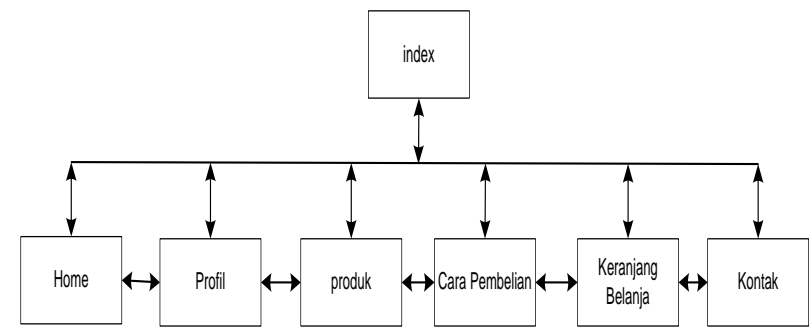

Gambar 9

Struktur Navigasi User

\section{B. Struktur Navigasi Tampilan Admin}

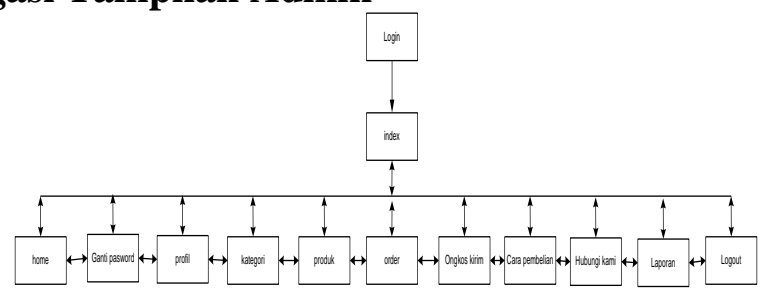

Gambar 10

Struktur Navigasi Admin

\section{KESIMPULAN}

Dari pembuatan aplikasi sistem informasi ini. Diperoleh kesimpulan sebagai berikut:

1. Mempermudah toko buku mempromosikan produk-produknya melalui website.

2. Sistem informasi penjualan berbasis web ini dapat memberikan kemudahan pada konsumen data mendapatkan informasi tentang buku yang ditawarkan.

3. Mengelola data-data buku lebih mudah dengan adanya sistem ini.

\section{DAFTAR PUSTAKA}

[1]. A.S, Rossa dan M. Shalahudin. 2013. Rekayasa Perangkat Lunak Terstruktur \& Berorientasi Objek. Bandung: Informatika.

[2]. Hadi, Mulya. 2006. 7 Jam Belajar Interaktif Dreamweaver 8 untuk Orang Awam. Palembang: Maxikom.

[3]. Hidayat, Rahmat. 2010. Cara Gratis Membangun Website Gratis. Jakarta: PT.Elex Media Komputindo.

[4]. Fathansyah. 2007. Buku Teks Komputer Basis Data. Bandung: Informatika.

[5]. Ikasari, Nining. 2011 perancangan sistem informasi jasa rental liquid transporter. Tangerang. Bina sarana informatika.

[6]. Ilamsyah. 2015 Materi 4: entity relationship. Tangerang: Perguraun tinggi Raharja 
[7]. Ilamsyah. 2015 Materi 9: perancangan database. Tangerang: Perguraun tinggi Raharja

[8]. Kadir, Abdul. 2008 Tuntunan Praktis Belajar Database Menggunakan MySQL. Yogyakarta: CV. Andi Offset.

[9]. Kadir, Abdul. 2009. Membuat Aplikasi Web dengan PHP + Database Mysql. Yogyakarta: Andi Yogyakarta.

[10]. Nugroho, adi. 2011 perancangan dan implementasi sistem basis data. Yogyakarta: andi

[11]. Nugroho, Bunafit. 2004. Aplikasi Pemrograman Web Dinamis dengan PHP dan MySQL. Yogyakarta: Gava Media.

[12]. Prihatna, Henky. 2005. Struktur Navigasi. Jakarta: PT. Elex Media Komputindo.

[13]. Raharjo, budi. 2011 membuat database mengunakan MySQL. Bandung: Informatika

[14]. Sibero, Alexander F.K. 2011. Kitab Suci Web Programming. Jakarta: Media Kom.

[15]. Simarmata, Janner. 2010. Rekayasa Perangkat Lunak. Yogyakarta: Andi Offset.

[16]. Soetam, Rizky. 2011. Konsep Dasar Rekayasa Perangkat Lunak. Jakarta: Prestasi Pustaka.

[17]. Sukarno, Mohamad. 2006. Membangun Website Dinamis Interaktif dengan PHPMySQL. Bekasi: Eska Media Press.

[18]. Sunarto, Andi. 2009. Seluk Beluk E-Commerce. Yogyakarta: Graha Ilmu. 